\title{
Silica depletion shut off the BIF factory
}

\author{
RUIMIN WANG ${ }^{1,}$ BING SHEN ${ }^{1}$
}

${ }^{1}$ Key Laboratory of Orogenic Belts and Crustal Evolution, MOE \& School of Earth and Space Sciences, Peking University, Beijing, China

The banded iron formation (BIF) is the signature of Archean and Paleoproterozoic deposits, and the its disappeared in 1.8 billion years ago $(\mathrm{Ga})$ marked a sharp change of environments. It has long been held that the disappearance of BIF might be related to the seawater depletion of $\mathrm{Fe}^{2+}$, probably due to the ocean oxidation or the development of oceanic euxinia (i.e. the Canfield Ocean model). However, more and more geochemical and sedimentological evidence indicates that the Proterozoic ocean was predominant ferruginous $\left(\mathrm{Fe}^{2+}\right.$ enriched) with the widespread sulfidic continental margins, and non-BIF ironstone deposits are common after $1.8 \mathrm{Ga}$, questioning the Fe-depletion interpretation for the disappearance of BIF. BIF is characterized by the rhythmic precipitation of iron-rich and silica-rich layers, requiring the sufficient supplies of both Fe and $\mathrm{Si}$. Here, we develop a model to show that the disappearance of BIF might be attributed to the seawater depletion of silica. In Proterozoic oceans where silicasecreting organisms were absent, inorganic silica precipitation might be the major process removing seawater $\mathrm{Si}$. The Fe redox cycle and $\mathrm{Si}$ cycle are coupled by the scavenging of seawater $\mathrm{Si}$ by $\mathrm{FeOOH}$ precipitation. We suggest active $\mathrm{Fe}$ redox cycle after $1.8 \mathrm{Ga}$ might have enhanced the efficiency of silica precipitation from seawater, lowering the seawater silica concentration. As such, BIF precipitation was prohibited by the insufficient supply of silica from seawater. In contrast, the non-BIF ironstone deposition was warranted by iron supply from ferruginous seawater. This model can also explain the reoccurrence of BIF in the Neoproterozoic Snowball Earth $(\sim 0.7 \mathrm{Ga})$, during which inactive Fe-redox cycle allowed the increase of seawater silica concentration in the ice-covered ocean. 